\title{
Epidemiological surveillance of colonising group B Streptococcus epidemiology in the Lisbon and Tagus Valley regions, Portugal (2005 to 2012): emergence of a new epidemic type IV/clonal complex 17 clone
}

C Florindo1, V Damião ${ }^{1,2}$, I Silvestre ${ }^{1,2,3}$, C Farinha ${ }^{2,3}$, F Rodrigues ${ }^{2,3}$, F Nogueira' ${ }^{2,3}$, F Martins-Pereira ${ }^{2,3}$, R Castro ${ }^{2,3}$, M J Borrego (M.Jose.Borrego@insa.min-saude.pt) ${ }^{1}$, I Santos-Sanches ${ }^{2}$, The Group for the Prevention of Neonatal GBS Infection ${ }^{4}$

1. Department of Infectious Diseases, National Institute of Health, Lisbon, Portugal

2. CREM, Departamento de Ciências da Vida, Faculdade de Ciências e Tecnologia, FCT, Universidade Nova de Lisboa, Caparica, Portugal

3. Medical Microbiology Unit, Instituto de Higiene e Medicina Tropical, IHMT, Universidade Nova de Lisboa, Lisbon, Portugal

4. The members of this group are listed at the end of the article

Florindo C, Damião V, Silvestre I, Farinha C, Rodrigues F, Nogueira F, Martins-Pereira F, Castro R, Borrego MJ, Santos-Sanches I, The Group for the Prevention of Neonatal GBS Infection. Epidemiological surveillance of colonising group B Streptococcus epidemiology in the Lisbon and Tagus Valley regions, Portugal (2005 to 2012): emergence of a new epidemic type IV/clonal complex 17 clone. Euro Surveill. 2014;19(23): pii=20825. Available online: http://www.eurosurveillance.org/ 2012): emergence of a new epidemicticle
ViewArticle.aspx?Articleld $=20825$

This study presents the serotype distribution and the antibiotic resistance profile of 953 colonising group B Streptococcus (GBS) recovered from women of child bearing age ( 15 to 49 years) between 2005 and 2012 in the Lisbon and Tagus Valley region, Portugal. Overall, serotypes Ia, II, III, and V were the most common, accounting 752 of the 953 isolates (about $80 \%$ ). However, there were changes in GBS distribution, in particular in the two last years of the study. Of note, the proportion of serotype IV isolates increased from $1 \%(2 / 148)$ in 2006 to $20 \%(19 / 97)$ in 2012 . Also, considerable proportions of serotype IV isolates from 2010 to 2012 were respectively resistant to erythromycin $(9 / 43 ; 21 \%)$ or clindamycin $(6 / 43 ; 14 \%)$. The identification of nine serotype IV isolates presenting a novel association with the clonal complex (CC) 17 lineage, involving a putative capsular switch, may accentuate their virulence potential and ecological success. Molecular analysis of this subgroup of isolates revealed the presence of rib, IS (insertion sequence) 861 and GBSi1 group II intron within the $C_{5}$ a peptidase gene $(s c p B)$ - laminin-binding protein gene $(\operatorname{lmb})$ region, reflecting high clonality and a putative common origin. A close surveillance of the emergent type IV/CC 17 isolates is crucial considering the potential impact over GBS treatment guidelines and capsular vaccine development.

\section{Introduction}

Streptococcus agalactiae, group B Streptococcus (GBS) is an opportunistic microbial agent of neonatal pneumonia, septicaemia and meningitis in human newborns [1]. GBS is also a significant cause of morbidity and mortality in non-pregnant adults, particularly those with underlying medical conditions and in the elderly
[1]. Up to $36 \%$ of pregnant women are anogenitally colonised, although the carrier status is considered dynamic during pregnancy $[1,2]$. In newborns, maternal GBS carriage has been recognised as the major risk factor of early onset disease (EOD, 47 days of age), but bacteria can also be acquired through horizontal nosocomial transmission [1].

Classification of GBS serotype is based on $10 \mathrm{immu-}$ nologically unique capsular polysaccharides (la, lb, II-IX), whose prevalence varies according to geographical location, time of study and ethnicity $[1,3]$. Thus, the continuous monitoring of circulating GBS isolates is important in assessing changes in GBS serotype distribution, which is essential for the development of polysaccharide-based vaccines suitable for different geographical areas [4,5]. Serotypes Ia, II, III and V have been the most frequently described in European countries such as the Czech Republic, France, Germany, Greece, Ireland, Italy, the Netherlands, Portugal, Sweden, and the United Kingdom [6], as well as in the United States (US) [7], whereas serotypes VI and VIII, to date scarcely found in these countries, could frequently be identified in Japan [8]. With the exception of a study carried out in Abu Dhabi, United Arab Emirates, where serotype IV predominated among colonised pregnant women (15/57, 26\% of the GBS isolates) [9], there are few reports among other countries worldwide of serotype IV as a predominant serotype both in cases of colonisation and infection [6-8,10-13].

Previous reports from Portugal, for the period from 2002 to $2007[6,12]$, have shown a low and stable prevalence of serotype IV $(6 / 269(2 \%)$ and $3 / 100(3 \%)$ among colonised women of reproductive age (15 to 49 
years). The same scenario was observed among neonatal (2/64 cases; 3\%) for the years 2000 to 2004 [12] and non-pregnant adult infections (2/225 cases; 1\%) from 2001 to 2008 [14]. After 2010, reports from Brazil Ireland and the US [15-18] revealed an increased prevalence of serotype IV in colonisation and infection, suggesting the possibility that this serotype could be emerging as an important pathogen, as happened with serotype V during the 1990s [19].

In this report we describe the annual serotype distribution and the antimicrobial susceptibility of colonising GBS isolated in the Lisbon and Tagus Valley region in Portugal from 2005 to 2012, revealing the increasing frequency of serotype IV and a novel serotype IV clone defined by its clonal complex (CC) 17 hypervirulent lineage, recently identified in Taiwan, France and the US $[10,16,20]$.

\section{Methods}

\section{Group B Streptococcus collection}

A total of 953 non-redundant GBS carriage isolates recovered from rectovaginal specimens of healthy women in reproductive age (668 pregnant) were included in this study. GBS were isolated according to the US Centers for Diseases Control and Prevention (CDC) guidelines $[\mathbf{2 1 , 2 2}]$. The Portuguese National Institute of Health and six tertiary hospitals (Maternidade Alfredo da Costa, Hospital Garcia de Orta, Hospital Dona Estefânia, Hospital CUF Descobertas, Hospital Fernando Fonseca and Hospital Distrital de Santarém) located in the Lisbon and Tagus Valley region, Portugal, participated in this survey between January 2005 and December 2012. GBS isolates were identified to the species level by standard criteria based on colony morphology, Gram staining, catalase test, and commercial group B Streptococcus latex-agglutination assays.

\section{Capsular serotyping}

All isolates were serotyped by slide agglutination using specific rabbit antisera against GBS polysaccharide antigens Ia, Ib, II to VIII (Essum $A B$ ) according to the instructions of the manufacturer. Non-serotypeable isolates were subjected to capsular (cps) genotyping, through the polymorphism analysis of $c p s D$ - $c p s E-c p s F$ region [6]. All serotype IV isolates were further confirmed through capsular genotyping. Non-typeable isolates after both serotyping and $c p s$ genotyping procedures were designated as NT.

\section{Antimicrobial susceptibility profile}

All GBS isolates were tested for penicillin G, erythromycin, clindamycin and vancomycin susceptibility by Epsilometer (E)-test, in accordance to the Clinical and Laboratory Standards Institute (CLSI) guidelines [23], to determine the minimum inhibitory concentration (MIC). The constitutive and inducible macrolide-lincosamidestreptogramin resistance phenotypes $\left(\mathrm{CMLS}_{B}\right.$ and $\mathrm{iML} S_{B}$, respectively) were identified by the double-disc diffusion method, as well the macrolide-specific efflux resistance phenotype $(M)[6,23]$. Macrolide resistance genes ermTR, ermB and mefA were also investigated by polymerase chain reaction (PCR) [6].

Considering that tetracycline is nowadays not recommended for the prophylaxis of GBS neonatal infection $[21,22]$, this antibiotic was not tested by all laboratories involved in the present study; consequently, only a subset of $372 / 953$ (39\%) GBS isolates was tested for tetracycline by disc-diffusion in accordance to the CLSI guidelines [23].

\section{Molecular analysis of serotype IV isolates}

In order to estimate the frequency of type IV isolates belonging to the sequence type (ST) 17 lineage, the presence of the $h v g A$ gene (encoding a surface adhesin characteristic of the hypervirulent GBS C(17) was achieved by PCR, as described elsewhere [24]. Serotype IV hvgA-positive isolates were further subjected to multilocus sequence typing (MLST) analysis [25], including the partial sequencing (about 500 bp) of seven housekeeping loci. Alleles of all loci were examined through the GBS MLST database (http://pubmlst. org/sagalactiae/) providing an allelic profile or ST.

Serotype IV characterisation also included the study of the Alp family, a major streptococcal antigen, by using multiplex PCR for direct identification of the alpha$C$, rib, epsilon and alp2-alp4 genes [26]. The prevalence of mobile genetic elements (MGES), IS (insertion sequence) 861, IS1381, IS1548 and GBSi1 group II intron within the $C_{5}$ a peptidase gene $(s c p B)$ - laminin-binding protein gene $(\operatorname{lm} b)$ region within type IV/CC17 isolates were also evaluated by PCR, as previously described $[27,28]$.

\section{FIGURE 1}

Serotype distribution among group B Streptococcus colonising isolates $(n=953)$ from women of reproductive age, Lisbon and Tagus Valley regions, Portugal, 2005-2012

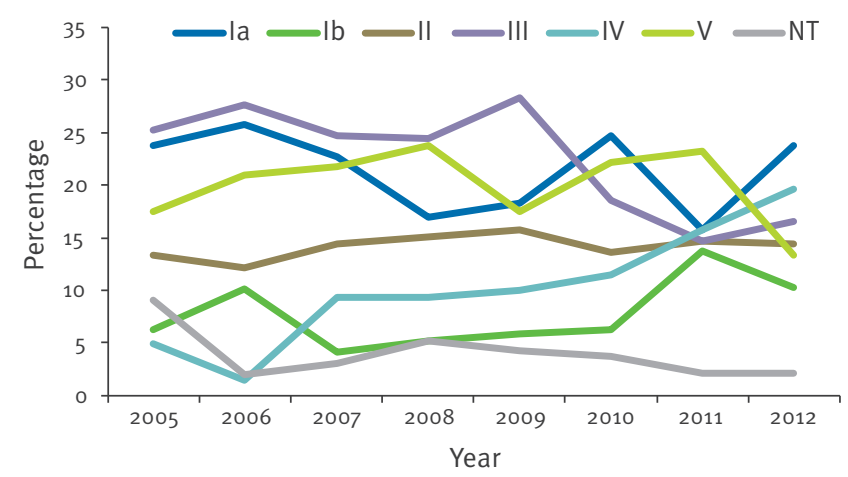

NT: non-typeable. 


\section{Results}

Annual distribution and frequency of serotypes Among the 953 isolates analysed, serotypes III, Ia, and $\mathrm{V}$ were the most frequent ones during the whole study period (2005-2012) (222 (23\%), 203 (21\%), and 192 (20\%), respectively), followed by serotypes II, IV, $\mathrm{Ib}$ and NT (135 (14\%), 89 (9\%), $72(8 \%)$ and 40 (4\%), respectively) (Figure 1). Serotypes VI to VIII were not found.

Variations in the distribution of GBS serotypes were observed, especially in 2011 and 2012, when the proportion of the serotypes III and V decreased whereas the proportion of serotypes IV and Ib increased. Indeed, a remarkable increase in serotype IV frequency has been observed, from $1 \%$ (2 of 148 isolates) in 2006 to $20 \%$ (19 of 97 isolates) in 2012 (20-fold), ranking this serotype as the second most detected in 2012 (Figure 1). In contrast, serotype II remained stable during the eight years study period, as its frequency ranged between $12 \%(n=116)$ and $16 \%(n=151)$.

\section{Susceptibility to antimicrobials}

Neither resistance nor reduced susceptibility to vancomycin or to penicillin $\mathrm{G}$, a first-line antibiotic for the prophylaxis and treatment of GBS infections, were detected.

For the total isolates in the 2005 to 2012 period, the percentage of GBS isolates that were resistant to erythromycin ranged from $14 \%(21 / 148)$ in 2006 to $23 \%(22 / 95)$ in 2011 , whereas the percentage of GBS isolates with resistance to clindamycin ranged from $6 \%(7 / 120)$ in 2009 to $18 \%(17 / 97)$ in 2012 (Figure 2 ). Of note, the higher resistance rates for both antibiotics respectively were observed in the two last years of the study (2011 and 2012) (Figure 2).

Among the $162 / 953$ (17\%) erythromycin-resistant isolates, 99/162 (61\%) displayed the $\mathrm{CMLS}_{\text {в }}$ phenotype, $56 / 162(35 \%)$ had the $\mathrm{iMLS}_{B}$, and the $M$ phenotype accounted for $7 / 162$ isolates (4\%). All of the $\mathrm{CMLS}_{\mathrm{B}}$ and $\mathrm{iMLS}_{\mathrm{B}}$ resistance phenotypes were conferred by the presence of the ermB and ermTR genes, respectively, whereas the $M$ phenotype was related to the presence of the mefA gene. Among the $372 \mathrm{GBS}$ isolates tested for tetracycline, $306(82 \%)$ were resistant to this antibiotic. Only 41/162 erythromycin-resistant GBS isolates were tested for tetracycline and all were resistant to the latter, which could be expected considering a putative horizontal gene transfer event involving the same conjugative transposon carrying both genetic resistance determinants [26]. We verified that the erythromycin $(n=162)$ and clindamycin $(n=98)$ resistant isolates involved multiple serotypes (Figure 2), despite the predominance of serotypes III and V from 2005 to 2008; however, the distribution profile remained very similar during the last three years (2010-2012), which could contradict the association between serotype III and macrolide resistance, previously demonstrated in
Portugal and Spain $[6,29]$. This situation constitutes a new scenario involving other serotypes, namely $\mathrm{Ib}$ and IV (Figure 2). In fact, in 2007 none of the four isolated strains serotyped as $\mathrm{lb}$ was resistant to macrolides, but during 2010 to $2012,19 / 28(68 \%)$ and $16 / 28$ (57\%) serotype $\mathrm{Ib}$ isolates were resistant to erythromycin and clindamycin, respectively; however, the number of Ib isolates was relatively low during this triennium. In 2006 and 2007, none of the 11 serotype IV isolates was resistant to erythromycin or clindamycin, whereas during 2010 to 2012, 9/43 (21\%) and 6/43 (14\%) serotype IV isolates were resistant to erythromycin and clindamycin, respectively.

\section{Frequency of clonal complex 17 lineage in serotype IV isolates}

Nine of $89(10 \%)$ serotype IV isolates collected over the eight-year period belonged to the hypervirulent $\mathrm{CC}_{17}$ lineage, and all displayed ST291 (a single locus variant of ST17); these nine isolates were recovered in $2008(n=3), 2009(n=1), 2010(n=1)$ and $2012(n=4)$. Concerning their susceptibility to antimicrobials, with one exception (one isolate from 2012, which was coresistant to clindamycin and erythromycin (MIC $\geq 256$ $\mu \mathrm{g} / \mathrm{ml})$ ), the remaining eight isolates were fully susceptible to penicillin $\mathrm{G}$, erythromycin, clindamycin, and

\section{FIGURE 2}

Percentage of the different group B Streptococcus serotypes among erythromycin (A) $(n=162)$ and clindamycin (B) $(n=98)$ resistant isolates, Lisbon and Tagus Valley regions, Portugal, 2005-2012
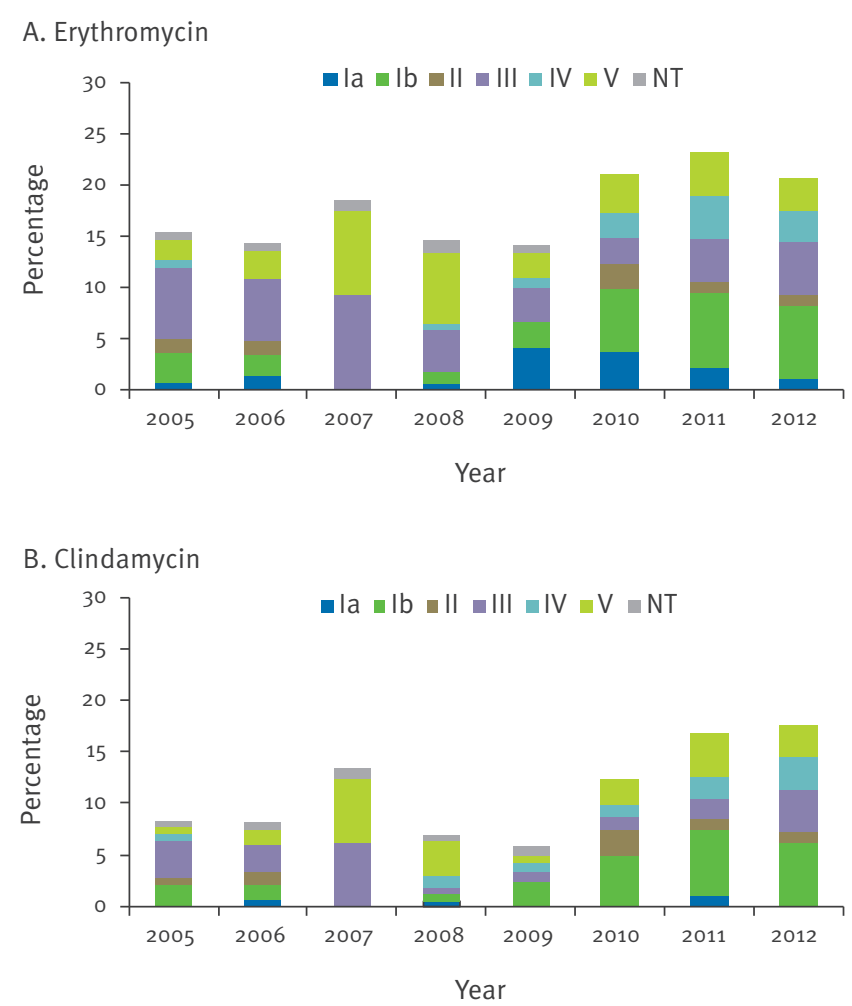

NT: non-typeable. 
vancomycin. All displayed the GBS surface protein rib gene, the GBSi1 in the $s c p B-\operatorname{lmb}$ intergenic region and the IS861. Excluding one serotype IV isolate from 2010, the insertion sequence IS1381 was not detected.

\section{Discussion}

The GBS capsule has long been recognised as one of the most important virulence factors. Variations of the polysaccharide structure allow the antigenic distinction of 10 different serotypes $[1,3]$. It has been reported that predominating serotypes change over time, vary by geographical region and ethnic origin and can be associated with different diseases. The existence of several serotypes together with their differential distribution constitutes a major obstacle for the development of a global and effective GBS vaccine to prevent GBS neonatal infections [4].

Due to its low prevalence in European countries and in the US, serotype IV was not selected for the development of capsular polysaccharide-based vaccines $[4,5]$. This situation has changed in the last decade, when some countries, including the US, saw the emergence of serotype IV among colonising and invasive GBS isolates $[15,16]$. This scenario may become risky if the emergence of serotype IV combines with antibiotic resistance, which was the case in our study where co-resistance to second-line macrolide antibiotics was observed in recent years (2010-2012). Corroborating our findings, resistance to macrolides and clindamycin has been described in the US [16] among invasive serotype IV isolates, predicting the emergence of serious problems for the intrapartum antibiotic prophylaxis in pregnant women allergic to penicillin. GBS serotype distribution changes and antibiotic resistance trends constitute emerging phenomena that emphasise the need for constant monitoring, in order to develop accurate GBS prevention strategies.

Another major concern is the association of serotype IV with the ST17 lineage identified in our study, supporting that previously described in a few other geographical regions, such as France, Taiwan and US $[10,16,20]$. It is worth noting that $\mathrm{ST}_{17}$ lineage was long considered as a homogeneous epidemic clone, almost exclusively composed by serotype III isolates, and characterised by its rapid global dissemination and successful adaptation to human neonates [30]. The origin of the novel association of $\mathrm{CC}_{17}$ with serotype IV can be due to an exchange of a $35.5 \mathrm{~kb}$ DNA segment containing the entire capsule operon, culminating in a type III to type IV capsular switch, as described by Bellais et al. [10]. This phenomenon predicts an important epidemiological success for this new clone. As both French and Portuguese type IV/CC17 GBS isolates were recently identified (after 2008), and as they share the same ST291, we could speculate on a common ancestor; however, this hypothesis needs further evaluation as this ST was also described among serotype IV invasive isolates from Minnesota, US [16].
In our study, the clonal origin hypothesis was evaluated through the screening of specific mobile genetic elements among our type IV/ST291 isolates, as their acquisition via recombination or horizontal transfer events are linked with the evolution and niche adaptation of bacterial species or particular clones. We verified that all type IV/ST291 isolates shared the same MGE profile composed by IS 861 and GBSi1 within the $s c p B$-Imb intergenic region in the absence of IS1381. Only one variant carrying this latter IS has been identified in 2010. This MGE profile strongly correlates to the evolutionary scheme proposed by Héry-Arnaud et al. [28] for the ST17 lineage; however, the existence of type IV/ST291 variants, containing IS1381 or displaying antibiotic resistance, suggests differential evolutionary status from a common ancestor.

In conclusion, a novel epidemic GBS type IV/CC 17 clone seems to be emerging through a putative clonal expansion among neonates and adults, as might have occurred since the 1960 s with type III/ST17, an 'epidemic clone' with a rapid global dissemination and adaptation to human neonates [30].

The sudden increase of GBS serotype IV detection in different countries does not rely on the emergence of type IV/CC17 only, as other genetic lineages (such as $\mathrm{CC}_{1}$ and $\mathrm{CC}_{23}$ ) or different types of pulsed-field gel electrophoresis have been identified, constituting the majority of the serotype IV isolates [15-18,20]. A careful surveillance of GBS type IV/ST291 emergence is recommended, in order to define its host specificity, tropism, virulence potential and antibiotic resistance phenotype.

Members of the Group for the Prevention of Neonatal GBS Infection

Emília Prieto (Instituto de Higiene e Medicina Tropical, Lisbon, Portugal), Filomena Nogueira and José Diogo (Hospital Garcia de Orta, Almada, Portugal), Luísa Sancho, Maria João Brito and Rosalina Barroso (Hospital Fernando Fonseca, Amadora, Portugal), Isabel Peres, Rosa Barros and Teresa Neto (Hospital D. Estefânia, Lisbon, Portugal), Eulália Galhano and Isabel Silva (Maternidade Bissaia Barreto, Coimbra; Portugal), Alexandra Almeida, Eugénia Fernandes and Paulo Sarmento (Maternidade Júlio Dinis, Porto, Portugal) and Isabel Lourenço (Maternidade Alfredo da Costa, Lisbon, Portugal).

\section{Acknowledgements}

The authors would like to thank to Albertina Paulino (Instituto Nacional de Saúde Dr. Ricardo Jorge), Jorge Lima (Hospital Cuf Descobertas, Lisbon, Portugal), Isabel Nogueira (Maternidade Alfredo da Costa, Lisbon, Portugal), Paula Caetano (Hospital Dona Estefânia, Lisbon Portugal and Hospital Cuf Descobertas, Lisbon Portugal), Isilda Rocha (Hospital Fernando da Fonseca, Amadora, Portugal), and Patrícia Guimarães (Instituto Higiene e Medicina Tropica, Lisbon, Portugal). Funding: This work was supported by projects PTDC/SAU-MII/105114/2008, Pest-OE/ BIA/Ulo457/2011-CREM, both funded by Fundação para a Ciência e a Tecnologia/Ministério da Educação e Ciência 
(FCT/MEC), Portugal, PROC 60839, funded by Fundação Calouste Gulbenkian, Portugal, and Grant 123/2007 funded by Comissão de Fomento da Investigação em Cuidados de Saúde, Portugal. CF was supported by PhD grant SFRH/ $\mathrm{BD} / 48231 / 2008$ (FCT/MEC).

\section{Conflict of interest}

None declared.

\section{Authors' contributions}

C. Florindo, V. Damião, I. Silvestre, C. Farinha, and members of the Group for the Prevention of Neonatal GBS Infection were involved in strain characterisation and data analysis. C. Florindo, M. J. Borrego, F. Martins-Pereira and I. SantosSanches were involved in the methodological design. Preparation of first draft: C. Florindo. Draft revision and approval: all.

\section{References}

1. Edwards MS, Nizet V. Group B streptococcal infections. In: Remington JS, Klein JO, Wilson CB, Nizet V, Maldonado YA, eds. Diseases of the fetus and newborn infant. 7 th ed. Philadelphia: Elsevier; 2011:419-69. http://dx.doi.org/10.1016/ B978-1-4160-6400-8.00012-2

2. Barcaite E, Bartusevicius A, Tameliene R, Kliucinskas M, Maleckiene L, Nadisauskiene R. Prevalence of maternal group $B$ streptococcal colonisation in European countries. Acta Obstet Gynecol Scand. 2008;87(3):260-71. http://dx.doi. org/10.1080/00016340801908759

3. Slotved HC, Kong F, Lambertsen L, Sauer S, Gilbert GL. Serotype IX, a proposed new Streptococcus agalactiae serotype. J Clin Microbiol. 2007;45(9):2929-36. http://dx.doi. org/10.1128/JCM.00117-07

4. Johri AK, Paoletti LC, Glaser P, Dua M, Sharma PK, Grandi G et al. Group B Streptococcus: global incidence and vaccine development. Nat Rev Microbiol. 200;4(12):932-42.

5. Rodriguez-Granger J, Alvargonzalez JC, Berardi A, Berner R, Kunze M, Hufnagel $M$ et al. Prevention of group B streptococcal neonatal disease revisited. The DEVANI European project. Eur J Clin Microbiol Infect Dis. 2012;31(9):2097-104. http://dx.doi. org/10.1007/s10096-012-1559-0

6. Florindo C, Viegas S, Paulino A, Rodrigues E, Gomes JP, Borrego MJ. Molecular characterization and antimicrobial susceptibility profiles in Streptococcus agalactiae colonizing strains: association of erythromycin resistance with subtype III-1 genetic clone family. Clin Microbiol Infect. 2010;16(9):1458-63. http://dx.doi. org/10.1111/j.1469-0691.2010.03106.x

7. Ippolito DL, James WA, Tinnemore D, Huang RR, Dehart MJ, Williams J et al. Group B streptococcus serotype prevalence in reproductive-age women at a tertiary care military medical center relative to global serotype distribution. BMC Infect Dis. 2010;10:336.

http://dx.doi.org/10.1186/1471-2334-10-336

8. Lachenauer CS, Kasper DL, Shimada J, Ichiman Y, Ohtsuka $\mathrm{H}$, Kaku M et al. Serotypes VI and VIII predominate among group B streptococci isolated from pregnant Japanese women. J Infect Dis. 1999; 179(4):1030-1033. http://dx.doi. org/10.1086/314666

9. Amin A, Abdulrazzaq YM, Uduman S. Group B streptococcal serotype distribution of isolates from colonized pregnant women at the time of delivery in United Arab Emirates. J Infect. 2002;45(1):42-6. http://dx.doi.org/10.1053/jinf.2001.0990

10. Bellais S, Six A, Fouet A, Longo M, Dmytruk N, Glaser P et al. Capsular switching in group B Streptococcus CC17 hypervirulent clone: a future challenge for polysaccharide vaccine development. J Infect Dis. 2012;206(11):1745-52. http:// dx.doi.org/10.1093/infdis/jis605

11. Fluegge K, Wons J, Spellerberg B, Swoboda S, Siedler A, Hufnagel $M$ et al. Genetic differences between invasive and noninvasive neonatal group B streptococcal isolates. Pediatr Infect Dis J. 2011;30(12):1027-31. http://dx.doi.org/10.1097/ INF.obo13e31822a2a1f

12. Martins ER, Pessanha MA, Ramirez M, Melo-Cristino J; Portuguese Group for the Study of Streptococcal Infections.
Analysis of group B streptococcal isolates from infants and pregnant women in Portugal revealing two lineages with enhanced invasiveness. J Clin Microbiol. 2007;45(10):3224-9. http://dx.doi.org/10.1128/JCM.01182-07

13. Figueira-Coelho J, Ramirez M, Salgado MJ, Melo-Cristino J. Streptococcus agalactiae in a large Portuguese teaching hospital: antimicrobial susceptibility, serotype distribution, and clonal analysis of macrolide-resistant isolates. Microb Drug Resist. 2004;10(1):31-6. http://dx.doi. org/10.1089/107662904323047772

14. Martins ER, Melo-Cristino J, Ramirez M; Portuguese Group for the Study of Streptococcal Infections. Dominance of serotype la among group B Streptococci causing invasive infections in nonpregnant adults in Portugal. J Clin Microbiol. 2012;50(4):1219-27. http://dx.doi.org/10.1128/JCM.05488-11

15. Diedrick MJ, Flores AE, Hillier SL, Creti R, Ferrieri P. Clonal analysis of colonizing group B Streptococcus, serotype IV, an emerging pathogen in the United States. J Clin Microbiol. 2010;48(9):3100-4. http://dx.doi.org/10.1128/JCM.00277-10

16. Ferrieri P, Lynfield R, Creti R, Flores AE. Serotype IV and invasive group $B$ streptococcus disease in neonates, Minnesota, USA, 2000-2010. Emerg Infect Dis. 2013;19(4):551-8.

17. Kiely RA, Cotter L, Mollaghan AM, Cryan B, Coffey A, Lucey B. Emergence of group B Streptococcus serotype IV in women of child-bearing age in Ireland. Epidemiol Infect. 2011;139(2):2368. http://dx.doi.org/10.1017/S0950268810001275

18. Palmeiro IK, Dalla-Costa LM, Fracalanzza SE, Botelho AC, da Silva Nogueira K, Scheffer MC et al. Phenotypic and genotypic characterization of group B streptococcal isolates in southern Brazil. J Clin Microbiol. 2010;48(12):4397-403. http://dx.doi. org/10.1128/JCM.00419-10

19. Elliott JA, Farmer KD, Facklam RR. Sudden increase in isolation of group B streptococci, serotype $V$, is not due to emergence of a new pulsed-field gel electrophoresis type. J Clin Microbiol. 1998;36(7):2115-6.

20. Tien N, Ho CM, Lin HJ, Shih MC, Ho MW, Lin HC. Multilocus sequence typing of invasive group B Streptococcus in central area of Taiwan. J Microbiol Immunol Infect. 2011;44(6):430-4. http://dx.doi.org/10.1016/j.jmii.2011.04.013

21. Schrag S, Gorwitz R, Fultz-Butts K, Schuchat A. Prevention of perinatal group $B$ streptococcal disease. Revised guidelines from CDC. MMWR Recomm Rep 2002;51(RR-11):1-22.

22. Verani JR, McGee L, Schrag SJ; Division of Bacterial diseases, National Center for Immunization and Respiratory Diseases, Centers for Disease Control and Prevention (CDC). MMWR Recomm Rep 2010;59(RR-10):1-36.

23. Clinical and Laboratory Standards Institute (CLSI). Performance Standards for Antimicrobial Disk Susceptibility Tests; Approved Standard-Tenth Edition. Mo2-A10. Wayne: CLSI; 2010.

24. Lamy MC, Dramsi S, Billoët A, Réglier-Poupet H, Tazi A, Raymond J et al. Rapid detection of the highly virulent group B Streptococcus ST-17 clone. Microbes Infect. 2006;8(7):1714-22. http://dx.doi.org/10.1016/j.micinf.2006.02.008

25. Jones N, Bohnsack JF, Takahashi S, Oliver KA, Chan MS, Kunst $\mathrm{F}$ et al. Multilocus sequence typing system for group B streptococcus. J Clin Microbiol. 2003;41(6):2530-6. http:// dx.doi.org/10.1128/JCM.41.6.2530-2536.2003

26. Gherardi G, Imperi M, Baldassarri L, Pataracchia M, Alfarone $\mathrm{G}$, Recchia S. Molecular epidemiology and distribution of serotypes, surface proteins, and antibiotic resistance among group B streptococci in Italy. J Clin Microbiol. 2007;45(9):290916. http://dx.doi.org/10.1128/JCM.00999-07

27. Al Safadi R, Amor S, Hery-Arnaud G, Spellerberg B, Lanotte $P$, Mereghetti L et al. Enhanced expression of Imb gene encoding laminin-binding protein in Streptococcus agalactiae strains harboring IS1548 in $s c p B$-Imb intergenic region. PLoS One. 2010;5(5):e10794. http://dx.doi.org/10.1371/journal. pone.0010794

28. Héry-Arnaud G, Bruant G, Lanotte P, Brun S, Rosenau $A$, van der Mee-Marquet $N$ et al. Acquisition of insertion sequences and the GBSiintron by Streptococcus agalactiae isolates correlates with the evolution of the species. J Bacteriol. 2005;187(17):6248-52. http://dx.doi.org/10.1128/ JB.187.17.6248-6252.2005

29. Martins ER, Andreu A, Correia P, Juncosa T, Bosch J, Ramirez $M$ et al. Group B streptococci causing neonatal infections in barcelona are a stable clonal population: 18-year surveillance. J Clin Microbiol. 2011;49(8):2911-18. http://dx.doi.org/10.1128/ JCM.00271-11

30. Sørensen UB, Poulsen K, Ghezzo C, Margarit I, Kilian M. Emergence and global dissemination of host-specific Streptococcus agalactiae clones. MBio. 2010;1(3):1-9. http:// dx.doi.org/10.1128/mBio.00178-10 